\title{
Cusack A.K. Venezuela, ALBA, and the Limits of Postneoliberal Regionalism in Latin America and the Caribbean. Palgrave Macmillan, 2019. 218 p.
}

\author{
А.В. Борейко \\ Институт Латинской Америки РАН, Москва, Российская Федерация
}

Для цитирования: Борейко А.B. Рецензия: Cusack A.K. Venezuela, ALBA, and the Limits of Postneoliberal Regionalism in Latin America and the Caribbean. Palgrave Macmillan, 2019. 218 р. // Вестник Российского университета дружбы народов. Серия: Международные отношения. 2020. Т. 20. № 2. 421-424. DOI: 10.22363/2313-0660-2020-20-2-421-424

Book review

\section{Cusack, A.K. (2019). Venezuela, ALBA, and the Limits of Postneoliberal Regionalism in Latin America and the Caribbean. Palgrave Macmillan, 218 p.}

\author{
A.V. Boreyko \\ Institute of Latin America, RAS, Moscow, Russian Federation
}

For citation: Boreyko, A.V. (2020). Book review: Cusack, A.K. (2019). Venezuela, ALBA, and the Limits of Postneoliberal Regionalism in Latin America and the Caribbean. Palgrave Macmillan, 218 p. Vestnik RUDN. International Relations, 20 (2), 421 - 424. DOI: 10.22363/2313-0660-2020-20-2-421-424

Ограниченность неолиберальной модели развития как глобального тренда стала очевидна после финансового кризиса 2008 г. В дальнейшем ситуация не улучшилась, темпы роста мирового ВВП так и не достигли докризисного уровня. В условиях «деглобализации» государства все чаще стали прибегать к политике экономического национализма, чтобы защитить отечественных производителей. Примером такого тренда стала торговая война между США и Китаем, «Брексит» и т. п. Эти процессы сопровождаются увеличением социально-экономического неравенства и ростом протестных настроений по всему миру.

В этой связи не теряет актуальности проблема изучения оптимальных моделей интеграции, которые позволили бы смягчить негативные последствия этого кризиса. Одним из любопытных примеров подобной модели является Боливарианский Альянс для народов нашей Америки (АЛБА), возникший в 2004 г. на волне антинеолиберального левого поворота в Латинской Америке. Альянс объединил Венесуэлу, Боливию, Никарагуа и Эквадор, а особое место в организации заняла Куба. За последние 15 лет АЛБА неоднократно становился предметом исследования как отечественных, так и зарубежных авторов.

Особенностью рецензируемой монографии доктора политической экономии стран Латинской Америки и Карибского бассейна, научного сотрудника Центра Латиноамериканских и карибских стран Лондонской школы экономических и политических наук

(C) Борейко А.В., 2019

This work is licensed under a Creative Commons Attribution 4.0 International License.

https://creativecommons.org/licenses/by/4.0/ 
Асы Кьюсака [Cusack 2019] является стремление автора преодолеть недостатки исследований своих предшественников, в частности предвзятость в оценках и акцент на изучении теоретической составляющей. Таким образом, рецензируемая работа нацелена на комплексный анализ как сильных, так и слабых сторон АЛБА с упором на эмпирику. Выходя за рамки политологии, А. Кьюсак использует междисциплинарный политико-экономический подход, существенно обогативший его работу. На протяжении семи глав автор двигается от общего к частному, от модели в целом до ее отдельных проектов.

В первой главе [Cusack 2019: 1-27] A. Кьюсак в общих чертах описывает причины возникновения АЛБА и дает краткие выводы по всем главам. По его мнению, этот проект регионального управления был создан как альтернатива американскому неолиберальному проекту АЛКА, направленному на создание зоны свободной торговли в регионе Латинской Америки и Карибского бассейна. Отличительными чертами АЛБА стали социальная ориентация, стремление к независимости от развитых стран и главенствующая роль государства в экономике.

Здесь же автор дает краткую характеристику «боливарианской революции» в Венесуэле. Он справедливо отмечает, что суть «социализма XXI века» состоит в достижении реальной демократии путем вовлечения широких масс в политическую и экономическую деятельность. Необходимым условием для этого является устранение структурного неравенства в доступе к общественным благам, то есть решение проблемы «социальной исключенности».

Исследованию организационной структуры АЛБА посвящена вторая глава [Cusack 2019: 27-57]. Сравнивая официальные документы с практикой управления, автор делает вывод, что за стройно прописанной системой органов власти скрывается экстраполяция венесуэльской административной модели на региональный уровень. К характерным чертам такой модели относится бессистемное принятие политических решений при бездействии формальных институтов. По мнению
А. Кьюсака, последствия такого подхода сделали Боливарианский Альянс «токсичным брендом» не только для других стран, но и для некоторых бывших и действующих участников.

Исследованию венесуэльской модели посвящена третья глава [Cusack 2019: 57-93]. Автор предполагает, что недостатки АЛБА коренятся в проблемах практической реализации «боливарианского социализма», который не смог достичь ни одной из поставленных целей. А. Кьюсак отмечает, что вместо диверсификации власти произошла ее концентрация в руках правящей партии, социализация экономической модели носила ограниченный характер и так же была нацелена на извлечение прибыли. Как следствие - широкое распространение получила коррупция и некомпетентное управление государственными предприятиями. Примечательно, что вопреки распространенному мнению о доминировании государственного сектора в экономике Венесуэлы, по данным автора, его доля снизилась, при этом в полной мере сохранились монокультурность и зависимость от нефтяного сектора.

По мнению А. Кьюсака, гражданское общество в реальности не имело возможности контролировать деятельность государственных и партийных чиновников, а институты участия превратились в механизмы личного обогащения. Президент Уго Чавес и его преемник, Николас Мадуро, продолжали поддерживать модель, несмотря на подобные негативные проявления, что в результате привело к ее деградации.

В то же время автор приводит пример более умеренного варианта «социализма XXI века», который сложился в Эквадоре. Здесь развитие социального государства происходило на основе компромисса с бизнесэлитами, а государство практически не прибегало к национализации предприятий. Кроме того, участие эквадорской стороны в АЛБА ограничилось созданием финансовой архитектуры, что позволило избежать катастрофической ситуации в экономике.

В четвертой главе представлена попытка создания так называемой «зоны честной торговли» [Cusack 2019: 93-119]. Автор 
справедливо отмечает, что в отличие от договоров о свободной торговле (ДСТ) торговый договор народов (ТДН) ограничивал рыночные механизмы интеграции и позволял участникам защищать наиболее уязвимые отрасли экономики. Однако, по мнению А. Кьюсака, ТДН в рамках АЛБА так и не был реализован в полной мере, прежде всего в связи с низкой взаимной дополняемостью экономик стран, входящих в Альянс.

Региональная финансовая система «сукре» стала предметом изучения в пятой главе [Cusack 2019: 119-153]. Эта система должна была уменьшить зависимость от доллара во взаимных расчетах, дав преимущество национальным компаниям за счет снижения транзакционных издержек. По мнению автора, «сукре» сыграла позитивную роль в увеличении торгового оборота в рамках АЛБА, хотя этот эффект был ограничен упомянутой ранее слабой взаимной экономической дополняемостью. При этом А. Кьюсак отмечает, что к 2016 г. кризис в Венесуэле сделал «сукре» экономически бессмысленной.

В шестой главе [Cusack 2019: 153-191] автор проводит исследование соглашения о льготных поставках венесуэльской нефти для стран Карибского бассейна под названием «Петрокарибе». А. Кьюсак считает, что «Петрокарибе» стала наиболее успешной программой, связанной с АЛБА, так как действительно помогла участникам преодолеть энергетический кризис, а также направить сэкономленные средства на развитие социальных и инфраструктурных проектов. По мнению автора, в случае дальнейшего обострения экономической ситуации Каракас может потребовать погашения накопившейся задолженности, поставив тем самым перспективы соглашения под вопрос.

В заключительной седьмой главе [Cusack 2019: 191-213] автор приходит к выводу, что помимо успехов в решении социальных задач
Боливарианский Альянс не достиг ни одной из поставленных целей. По мнению А. Кьюсака, причиной неудачи стала неспособность руководства Боливарианской Республики преодолеть «голландскую болезнь». В частности, когда на определенном этапе реформ рентноориентированная модель развития вступила в противоречие с принципами «социализма XXI века», власти предпочли не менять модель, так как ресурсов было достаточно. Политическое и экономическое доминирование Венесуэлы в АЛБА привело к распространению национального кризиса на всю организацию. Таким образом, понятие «постнеолиберализм» носит во многом условный характер.

Кратко резюмируя вышесказанное, отметим, что А. Кьюсаку удалось справиться с поставленной задачей. Работа отличается системным, многоуровневым характером, при котором предмет исследования оказывается удачно «вписан» в глобальный и региональный контексты, при этом показаны место и роль каждого проекта. Несомненно, ценным является использование большого массива эмпирических данных, которые подкрепляют гипотезу автора о несоответствии заявленных целей АЛБА и их реализации.

Следует отметить, что работа не лишена некоторых недостатков. К ним можно отнести недостаточное внимание, уделяемое автором одному из наиболее важных участников, ближайшему союзнику Венесуэлы - Кубе. Кроме того, А. Кьюсак слишком общо описывает саму концепцию «социализма XXI века», упоминая в качестве ее идейного предтечи экономиста Иштвана Месароша, однако упуская из виду развитие данной теории в работах таких мыслителей, как Хайнц Дитерих, Марта Харнеккер и др.

Хочется надеяться, что в дальнейшем эти пробелы будут восполнены, позволив тем самым дать еще более точную оценку АЛБА и ее участникам.

Поступила в редакцию / Received: 08.11.2019 Принята к публикации / Accepted: 24.12.2019 


\section{Библиографический список}

Cusack A.K. Venezuela, ALBA, and the Limits of Postneoliberal Regionalism in Latin America and the Caribbean. Palgrave Macmillan, 2019.

\section{References}

Cusack, A.K. (2019). Venezuela, ALBA, and the Limits of Postneoliberal Regionalism in Latin America and the Caribbean. Palgrave Macmillan.

Сведения об авторе: Борейко Антон Владимирович - научный сотрудник Центра политических исследований Института Латинской Америки Российской академии наук (e-mail: polidekt@gmail.com).

About the author: Boreyko Anton Vladimirovich - Research Fellow, Center for Political Studies, Institute of Latin America, Russian Academy of Sciences (e-mail: polidekt@gmail.com). 